\title{
Mesoporous Ce-Zr mixed oxides for selective oxidation of styrene in liquid phase
}

\author{
P. R. G. Nallappa Reddy ${ }^{1,2} \cdot$ Bolla Govinda Rao ${ }^{1,2} \cdot$ Tumula Venkateshwar Rao ${ }^{1,2} \cdot$ Benjaram M. Reddy ${ }^{1,2} \mathbb{C}$
}

Received: 17 March 2020 / Accepted: 8 May 2020 / Published online: 18 May 2020

(c) The Author(s) 2020

\begin{abstract}
This work reports the synthesis of mesoporous $\mathrm{Ce}_{1-x}-\mathrm{Zr}_{x} \mathrm{O}_{2-\delta}(x=0.5$ and 0.8$)$ mixed oxides with distinct $\mathrm{Ce} / \mathrm{Zr}$ mole ratio by inverse micelle template method and their catalytic exploration for epoxidation of styrene in isopropanol solvent using TBHP as the oxidant. Among various catalysts investigated, the $\mathrm{Ce}_{0.8} \mathrm{Zr}_{0.2} \mathrm{O}_{2}$ combination catalyst exhibited best catalytic activity with $\sim 98 \%$ conversion and $\sim 90 \%$ selectivity to styrene epoxide. The synthesized $\mathrm{Ce}-\mathrm{Zr}$ mixed oxide catalysts were characterized by various state-of-the-art techniques. Characterization studies revealed that $\mathrm{Ce} / \mathrm{Zr}$ mole ratio has an imperative influence on the physicochemical properties such as surface area, oxygen vacancy concentration, and redox nature. Interestingly, catalytic efficiency was significantly improved with the increase of $\mathrm{Ce}$ and decrease of $\mathrm{Zr}$ content in the $\mathrm{Ce}-\mathrm{Zr}$ mixed oxides. Catalytic efficiency and distribution of the products for styrene oxidation under various conditions such as reaction time, solvent, temperature, and styrene to TBHP mole ratio were also evaluated. Reusability of the highly active $\mathrm{Ce}_{0.8} \mathrm{Zr}_{0.2} \mathrm{O}_{2}$ mixed oxide catalyst was also demonstrated.
\end{abstract}

Keywords Ceria $\cdot$ Styrene $\cdot$ Styrene epoxide $\cdot$ Oxygen vacancy $\cdot$ Redox properties

\section{Introduction}

Catalytic oxidation of styrene is considered as a popular reaction in the chemical and petrochemical industries, because the delivered oxygenated products are expedient and key intermediates for the synthesis of plasticizers, perfumes, drugs, agrochemicals, and pharmaceuticals [1, 2]. The literature assessment demonstrates that the catalytic oxidation of styrene produces benzaldehyde along with styrene epoxide [3]. Thus, achieving high selectivity to one of these products has been an everlasting topic in the field of heterogeneous catalysis. In the present investigation, our primary aim was to achieve high selectivity to styrene epoxide rather than benzaldehyde, owing to numerous applications of the product [4]. For example, epoxides are considered as key building blocks for the production of various organic

Benjaram M. Reddy

bmreddy@iict.res.in; mreddyb@yahoo.com

1 Catalysis and Fine Chemicals Department, CSIRIndian Institute of Chemical Technology, Uppal Road, Hyderabad 500 007, India

2 Academy of Scientific and Innovative Research, CSIR-IICT, Hyderabad, India products including glycols, alcohols, carbonyl compounds, alkanolamines, and polymers [5]. Traditionally, styrene oxidation was accomplished by employing organic peracid as an oxidant. However, utilization of such kinds of oxidants is no longer acceptable in the chemical industry due to their harmful nature to the environment [6].

In general, hydrogen peroxide $\left(\mathrm{H}_{2} \mathrm{O}_{2}\right)$, molecular oxygen $\left(\mathrm{O}_{2}\right)$, and tert-butyl hydroperoxide (TBHP) have been used as optional oxidants to explore the styrene oxidation $[3,7$, 8]. But, the selection of suitable oxidant is crucial to conduct the oxidation of styrene, because it shows enormous influence on the conversion and selectivity of reaction products. It is evident from the literature that TBHP has been identified as one of the promising oxidants for styrene oxidation since it relatively furnished high selectivity to styrene epoxide compared to other oxidants [9]. The disadvantage associated with $\mathrm{H}_{2} \mathrm{O}_{2}$ is that it has the ability to decompose at high temperature, thereby shows poor selectivity in the styrene oxidation [10]. In contrast, high oxidation capability of molecular $\mathrm{O}_{2}$ could provide more side products. Therefore, in this study, TBHP has been selected as the appropriate oxidant to perform the styrene epoxidation reaction.

In recent times, numerous heterogeneous catalysts have been explored for styrene oxidation using appropriate 
oxidants. It was found from these studies that the selectivity of products is strongly dependent on the nature of the catalytic system. For instance, $\mathrm{Co}_{3} \mathrm{O}_{4}[11], \mathrm{Mg} / \mathrm{Co} / \mathrm{Al}$ hydrotalcites [8], polyoxometalates [12], $\mathrm{Mg}-\mathrm{Cu}$ ferrite [13], and $\mathrm{BaFe}_{2} \mathrm{O}_{4}$ [7] catalysts are highly selective to benzaldehyde product. In contrast, $\mathrm{Mn}$ and Co oxides [3], $\mathrm{Cu}$-doped hydrotalcites [14], Cu-HMS [9], CuO/CoAl-HT [15], Co/nitrogen doped hollow spheres [16], and $\mathrm{Au}-\mathrm{TiO}_{2}$ nano particles [17] showed high selectivity to styrene epoxide. Owing to their attractive properties such as high surface area, tunable pore size, pore volume, and morphology, mesoporous metal oxides are playing a key role in the area of catalysis [3, 18]. For example, higher surface area of mesoporous metal oxides accompanying more number of active sites direct to excellent activity than that of their non-porous analogues $[19,20]$. One of the favourable properties of mesoporous metal oxides is the high adsorption ability of the substrate on the catalytic surface which results in excellent catalytic performance [21].

Ceria $\left(\mathrm{CeO}_{2}\right)$-based mixed oxides have been employed extensively as potential candidates for many catalytic applications due to their outstanding properties [22-25]. Doping of $\mathrm{Zr}$ into the $\mathrm{CeO}_{2}$ lattice is an effective strategy to manipulate the physicochemical properties like oxygen storage capacity, redox property, concentration of oxygen vacancies, and thermal stability of the ceria, thereby enlarging for better catalytic activity in many oxidation reactions $[26,27]$. The main goal of this work was to explore the consequence of $\mathrm{Ce} / \mathrm{Zr}$ mole ratio and morphology of mixed oxides on the physicochemical properties and catalytic activity for styrene oxidation. Accordingly, we have synthesized mesoporous $\mathrm{CeO}_{2}-\mathrm{ZrO}_{2}$ mixed oxides with different $\mathrm{Ce} / \mathrm{Zr}$ mole ratios by inverse micelle template method. A systematic physicochemical characterisation of the synthesized catalysts has been accomplished using X-ray diffraction (XRD), Brunauer-Emmet-Teller (BET) surface area, Raman spectroscopy, X-ray photoelectron spectroscopy (XPS), Field emission scanning electron microscopy (FE-SEM), and $\mathrm{H}_{2}$-temperature programmed desorption $\left(\mathrm{H}_{2}\right.$-TPR) techniques.

\section{Experimental}

\section{Catalyst preparation}

Mesoporous $\mathrm{Ce}_{1-x}-\mathrm{Zr}_{\mathrm{x}} \mathrm{O}_{2-\delta}(x=0.5$ and 0.8$)$ mixed oxides with different $\mathrm{Ce} / \mathrm{Zr}$ mole ratios along with pure $\mathrm{CeO}_{2}$ and $\mathrm{ZrO}_{2}$ were synthesized by adopting an inverse micelle method [28]. In a typical synthesis, appropriate amounts of corresponding metal precursors, namely, $\mathrm{Ce}\left(\mathrm{NO}_{3}\right)_{4} \cdot 6 \mathrm{H}_{2} \mathrm{O}$ (Aldrich, AR grade), $\mathrm{ZrO}\left(\mathrm{NO}_{3}\right)_{2} \cdot \mathrm{xH}_{2} \mathrm{O}$ (Sigma Aldrich, AR grade), and butanol were taken in a beaker. Later, desirable amount of poly(ethylene glycol)blockpoly(propylene glycol)-block-poly(ethylene glycol) (P123) and concentrated nitric acid $\left(\mathrm{HNO}_{3}\right)$ were added to the above solution and stirred at room temperature until it completely dissolved. The resulting clear solution was heated at $393 \mathrm{~K}$ for $3 \mathrm{~h}$ under stirring condition. The obtained black powder was washed with excess ethanol, centrifuged, and dried in a vacuum oven overnight. At the end, the dried black powder was subjected to a heating cycle. First, they were heated at $423 \mathrm{~K}$ for $12 \mathrm{~h}$ and cooled down to room temperature under ambient conditions. The obtained material was then subjected to the following heating cycle to obtain differently calcined materials: $523 \mathrm{~K}$ for $3 \mathrm{~h}, 623 \mathrm{~K}$ for $2 \mathrm{~h}, 723 \mathrm{~K}$ for $2 \mathrm{~h}$, and $823 \mathrm{~K}$ for $1 \mathrm{~h}$, respectively.

\section{Catalyst characterization}

Powder XRD patterns of the prepared samples were recorded on a Rigaku diffractometer using $\mathrm{Cu} \mathrm{K} \alpha$ radiation $(1.540 \AA$ ), operated at $40 \mathrm{kV}$ and $40 \mathrm{~mA}$. The diffractograms were recorded in the $2 \theta$ range of $10-80^{\circ}$ with a $2 \theta$ step size of $0.02^{\circ}$ and a step time of $2.4 \mathrm{~s}$. The XRD phases present in the samples were identified with the help of Powder Diffraction File-International Centre for Diffraction Data (PDFICDD). The average crystallite size and lattice parameter of the prepared samples were calculated using the full width at half maximum (FWHM) of the (111) peak using the Debye-Scherer equation and the cubic indexation methods, respectively.

The Brunauer-Emmett-Teller (BET) surface area of the samples was determined by $\mathrm{N}_{2}$ adsorption on a Micromeritics Gemini 2360 instrument. Before the analysis, the samples were oven-dried at $393 \mathrm{~K}$ for $12 \mathrm{~h}$ and flushed with argon gas for $2 \mathrm{~h}$ to remove any surface-adsorbed residue. Surface area was calculated by utilizing the desorption data. Raman spectra of the samples were recorded on a Horiba Jobin-Yvon HR800 Raman spectrometer equipped with a liquid-nitrogen cooled charge coupled device (CCD) detector and a confocal microscope. The emission line at $638 \mathrm{~nm}$ from $\mathrm{Ar}^{+}$laser (Spectra Physics) was focused on the sample under the microscope with the diameter of the analysed spot being $\sim 1 \mu \mathrm{m}$, under the ambient conditions. The time of acquisition was adjusted according to the intensity of Raman scattering. The wavenumber values obtained were precise to within $2 \mathrm{~cm}^{-1}$.

The XPS measurements were performed on a PHI 5400 instrument. $\mathrm{Al} \mathrm{K} \alpha$ radiation $(1486.6 \mathrm{eV}) \mathrm{X}$-ray source was used for XPS analysis and at a pressure lower than $10^{-7}$ Torr. The sample preparation for XPS analysis involves mounting of a few grams of sample on a carbon tape supported with a silica plate. The resultant plate supported with a holder is placed in the vacuum chamber of Thermo K-Alpha XPS instrument before the start of analysis. Thermo-Avantage Software was 
used for XPS analysis of the prepared samples. The binding energies of $\mathrm{Ce}, \mathrm{Zr}$, and $\mathrm{O}$ were charge-corrected with respect to the adventitious carbon $(\mathrm{C} 1 \mathrm{~s})$ peak at $284.6 \mathrm{eV}$. Flood gun was used to remove the static charge that developed on the sample surface during XPS analysis. FE-SEM studies were performed using a JEOL-7610F electron microscope to examine surface morphology, and the energy dispersive X-ray analysis (EDX) was used to determine the elemental composition of samples with OXFORD Inca detector interfaced at $5 \mathrm{kV}$.

The reducibility of the synthesized samples was estimated by $\mathrm{H}_{2}$-TPR analysis, using a thermal conductivity detector of a gas chromatograph (Schimadzu). Approximately $30 \mathrm{mg}$ of the samples were loaded in an isothermal zone of the reactor and were treated in a helium gas flow at $400 \mathrm{~K}$ followed by cooling to room temperature. After that, flow of the He was switched to $5 \% \mathrm{H}_{2} / \mathrm{Ar}$ with a rate of $20 \mathrm{~mL} \mathrm{~min}^{-1}$ and the temperature was linearly increased to $1073 \mathrm{~K}$ at a heating ramp of $5 \mathrm{~K} \mathrm{~min}^{-1}$, keeping all the parameters un-changed. The hydrogen consumption during the reduction process was estimated by passing the effluent gas through a molecular sieve trap to remove the produced water and was analysed by gas chromatography using a TCD.

\section{Catalytic activity test}

The catalytic efficiency of prepared mesoporous mixed oxides was evaluated for liquid phase oxidation of styrene using TBHP as the oxidant. Typically, a mixture of styrene (4 mmol), TBHP, isopropanol ( $3 \mathrm{ml})$, and the catalyst $(50 \mathrm{mg})$ was charged into a $10-\mathrm{ml}$ round-bottom flask. Then, the reaction mixture in the round-bottom flask was agitated at $1000 \mathrm{rpm}$ and the process was continued for desired time at $353 \mathrm{~K}$. After completion of the reaction, the liquid products and the catalyst were separated by centrifugation. The collected products were analysed by GC equipped with a BP-20 (wax) capillary column and a flame ionization detector. The products were confirmed by GC-MS equipped with a DB-5 capillary column and mass selective detector. The reaction products were also confirmed by injecting the corresponding authentic compounds in the GC. To check the reusability of the catalysts, after completion of reaction the catalyst was separated by centrifugation and washed with ethanol to remove the products adhered to the surface of the catalyst. The resulting sample was dried at $393 \mathrm{~K}$ for $12 \mathrm{~h}$, and then reused directly for the next run.

\section{Results and discussion}

\section{XRD and BET analysis}

Figure 1 shows the XRD profiles of calcined $\mathrm{Ce}_{1-x}-\mathrm{Zr}_{x} \mathrm{O}_{2-\delta}$ $(x=0.5$ and 0.8$)$ mixed oxides along with bare $\mathrm{CeO}_{2}$ and
$\mathrm{ZrO}_{2}$. Interestingly, distinct XRD patterns were observed for both mesoporous mixed oxide samples. The high $\mathrm{Ce}$ content $\mathrm{Ce}_{0.8} \mathrm{Zr}_{0.2} \mathrm{O}_{2}$ sample displayed XRD lines corresponding to (111), (200), (220), (311), (331), and (400) planes, which are characteristic of the fluorite like cubic structure of $\mathrm{CeO}_{2}[29,30]$. Further, no XRD lines related to $\mathrm{ZrO}_{2}$ phase were noticed for this sample indicating the formation of solid solution. In contrast, we observed XRD lines pertaining to mixed phases of $\mathrm{CeO}_{2}$ and $\mathrm{ZrO}_{2}$ in the XRD profile of $\mathrm{Ce}_{0.5} \mathrm{Zr}_{0.5} \mathrm{O}_{2}$ sample indicating that $\mathrm{Zr}$ is not completely doped into the $\mathrm{CeO}_{2}$ lattice. On the other hand, mesoporous $\mathrm{CeO}_{2}$ showed XRD lines related to (111), (200), (220), (311), (331), and (400) planes, confirming the fluorite cubic structure of $\mathrm{CeO}_{2}$. On the similar lines, tetragonal $\mathrm{ZrO}_{2}$ phase was identified in the XRD profile of mesoporous $\mathrm{ZrO}_{2}$ [29]. No big change in the XRD patterns of the catalyst after catalytic runs was noted indicating that there is no change in the catalyst structure during catalytic evaluation.

To determine the specific surface area of the prepared mixed oxides, we have undertaken the BET analysis of the samples. The achieved BET results of the corresponding samples are illustrated in Table 1. Mixed oxides are expected to show larger BET surface areas than their individual single oxides, which is due to the cooperative effect of respective oxides in the final mixed oxide (Table 1). The existence of strong synergetic interaction between the foreign metal oxide and the host metal oxide is the key reason for enhancement in the surface area for mixed oxides. Interestingly, the specific surface area of the doped $\mathrm{CeO}_{2}$ was found to enhance

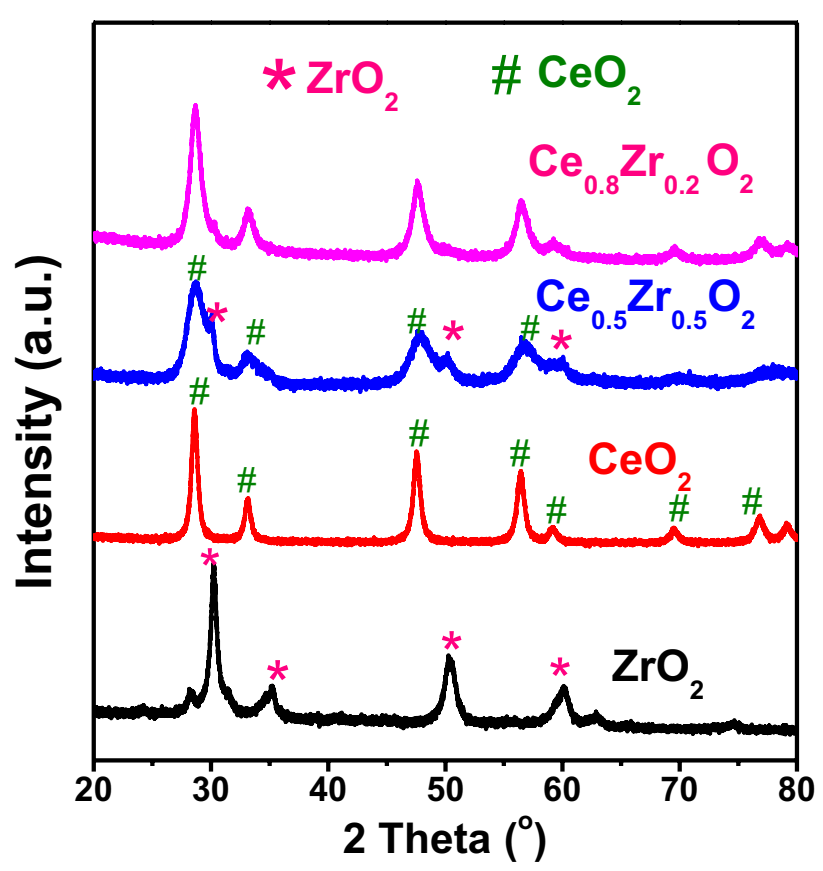

Fig. 1 Powder XRD profiles of pure $\mathrm{CeO}_{2}, \mathrm{Ce}_{0.5} \mathrm{Zr}_{0.5} \mathrm{O}_{2}$, and $\mathrm{Ce}_{0.8} \mathrm{Zr}_{0.2} \mathrm{O}_{2}$ samples 
Table 1 BET specific surface area (S) and Raman shift of various catalysts

\begin{tabular}{lrl}
\hline Sample & $\mathrm{S}\left(\mathrm{m}^{2} \mathrm{~g}^{-1}\right)$ & $\begin{array}{l}\text { Raman } \\
\text { shift } F_{2 \mathrm{~g}} \\
\left(\mathrm{~cm}^{-1}\right)\end{array}$ \\
\hline $\mathrm{CeO}_{2}$ & $38.4 \pm 3$ & 457 \\
$\mathrm{Ce}_{0.5} \mathrm{Zr}_{0.5} \mathrm{O}_{2}$ & $71.6 \pm 2$ & 465 \\
$\mathrm{Ce}_{0.8} \mathrm{Zr}_{0.2} \mathrm{O}_{2}$ & $137.1 \pm 2$ & 473 \\
$\mathrm{Ce}_{0.2} \mathrm{Zr}_{0.8} \mathrm{O}_{2}$ & $50.5 \pm 2$ & - \\
$\mathrm{ZrO}_{2}$ & $28.2 \pm 3$ & - \\
\hline
\end{tabular}

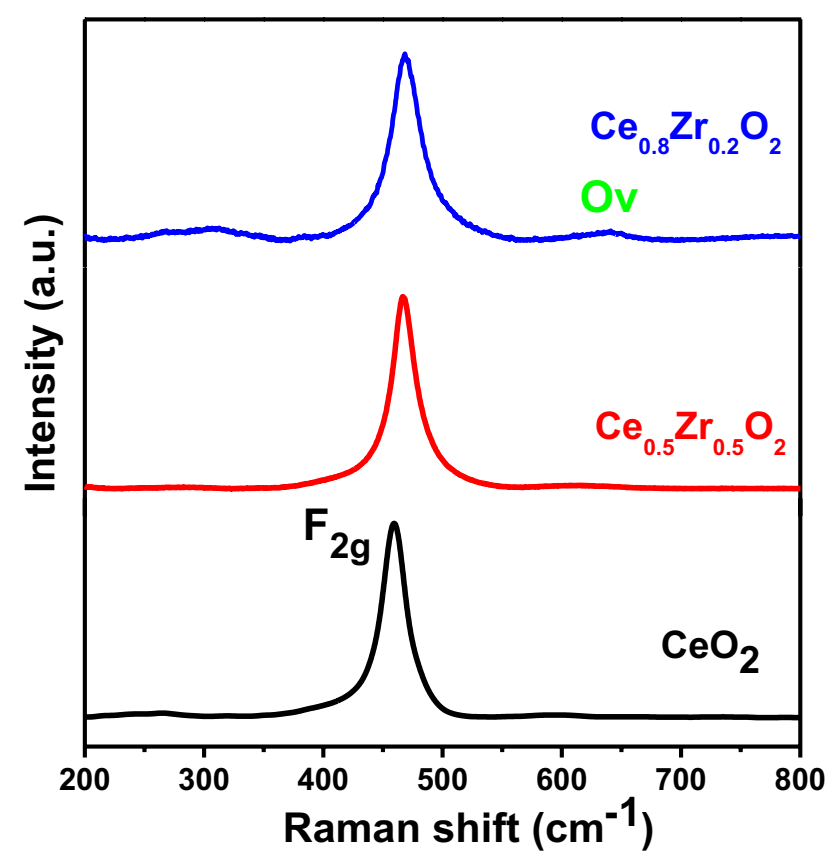

Fig. 2 Raman spectra of pure $\mathrm{CeO}_{2}, \mathrm{Ce}_{0.5} \mathrm{Zr}_{0.5} \mathrm{O}_{2}$, and $\mathrm{Ce}_{0.8} \mathrm{Zr}_{0.2} \mathrm{O}_{2}$ samples

with the increase of $\mathrm{Ce}$ content. The specific surface areas of $\mathrm{ZrO}_{2}, \mathrm{CeO}_{2}, \mathrm{Ce}_{0.5} \mathrm{Zr}_{0.5} \mathrm{O}_{2}$, and $\mathrm{Ce}_{0.8} \mathrm{Zr}_{0.2} \mathrm{O}_{2}$ samples were found to $\mathrm{be} \sim 28.2, \sim 38.4, \sim 71.6$, and $\sim 137.1 \mathrm{~m}^{2} / \mathrm{g}$, respectively.

\section{Raman studies}

Raman spectroscopy was employed to understand the structural properties of mesoporous $\mathrm{Ce}-\mathrm{Zr}$ mixed oxides. Raman spectra of $\mathrm{Ce}_{0.5} \mathrm{Zr}_{0.5} \mathrm{O}_{2}$ and $\mathrm{Ce}_{0.8} \mathrm{Zr}_{0.2} \mathrm{O}_{2}$ mixed oxides along with $\mathrm{CeO}_{2}$ are shown in Fig. 2. We observed a sharp intense Raman band located at $465 \mathrm{~cm}^{-1}$ for all the samples, which indicates the presence of the Raman-active $\mathrm{F}_{2 \mathrm{~g}}$ mode of fluorite structured $\mathrm{CeO}_{2}$ with the space group Fm3m (Supported by XRD results) [31]. Further, we did not notice any Raman bands related to $\mathrm{ZrO}_{2}$ phase in the investigated Raman region for both $\mathrm{Ce}-\mathrm{Zr}$ mixed oxides. In particular,
$\mathrm{F}_{2 \mathrm{~g}}$ band of $\mathrm{Ce}_{0.5} \mathrm{Zr}_{0.5} \mathrm{O}_{2}$ and $\mathrm{Ce}_{0.8} \mathrm{Zr}_{0.2} \mathrm{O}_{2}$ is significantly shifted and broadened with respect to pure $\mathrm{CeO}_{2}$, which is more pronounced in the case of $\mathrm{Ce}_{0.8} \mathrm{Zr}_{0.2} \mathrm{O}_{2}$ mixed oxide. The shift in $\mathrm{F}_{2 \mathrm{~g}}$ mode is probably due to the variation in the $\mathrm{M}-\mathrm{O}$ vibration frequency caused by the incorporation of $\mathrm{Zr}^{4+}$ ions into the $\mathrm{CeO}_{2}$ lattice. Ceria-based samples typically show a Raman band in the range of $\sim 580-650 \mathrm{~cm}^{-1}$, corresponding to the presence of oxygen vacancy defects in the $\mathrm{CeO}_{2}[32,33]$. To our delight, only high $\mathrm{Ce}$ content sample i.e. $\mathrm{Ce}_{0.8} \mathrm{Zr}_{0.2} \mathrm{O}_{2}$ showed a prominent Raman peak at $\sim 620 \mathrm{~cm}^{-1}$ indicating the presence of oxygen vacancies. It is a well-established fact in the literature that oxygen vacancies play a key role in the oxidation reactions.

\section{FE-SEM and XPS analysis}

Morphological evolution of the synthesized samples was scrutinized by FE-SEM. The corresponding FE-SEM images of various catalysts are shown in Fig. 3. It can be clearly seen from Fig. 3 that pure $\mathrm{CeO}_{2}$ and $\mathrm{ZrO}_{2}$ show mesoporous structure. Interestingly, no apparent variation in the structure of $\mathrm{Ce}-\mathrm{Zr}$ mixed oxides with different $\mathrm{Ce} / \mathrm{Zr}$ ratios was noticed. This result demonstrates that the introduction of dopant into the $\mathrm{CeO}_{2}$ lattice did not alter the original morphology of ceria. It is clear from the figure that both $\mathrm{Ce}-\mathrm{Zr}$ mixed oxides, namely, $\mathrm{Ce}_{0.5} \mathrm{Zr}_{0.5} \mathrm{O}_{2}$ and $\mathrm{Ce}_{0.8} \mathrm{Zr}_{0.2} \mathrm{O}_{2}$ show mesoporous structure.

Figure 4 represent the deconvoluted $\mathrm{Ce} 3 d$ core level spectra of $\mathrm{Ce}-\mathrm{Zr}$ mixed oxides including pure $\mathrm{CeO}_{2}$. The Ce $3 d \mathrm{XP}$ spectra are complex, which is due to the mixing of $\mathrm{O} 2 p$ and $\mathrm{Ce} 4 f$ levels. The peaks represented with $\mathrm{u}$ indicate $3 d_{3 / 2}$ spin-orbit states and those labelled by ' $\mathrm{v}$ ' correspond to $3 d_{5 / 2}$ contributions. As shown in Fig. 4, the peaks labelled by $\mathrm{u}^{\prime}$ and $\mathrm{v}^{\prime}$ represent the $\mathrm{Ce}^{3+}$ with the electronic configuration of $3 d^{10} 4 f^{1}$ and other bands labelled with $\mathrm{u}, \mathrm{u}^{\prime \prime}, \mathrm{u}^{\prime \prime \prime}, \mathrm{v}, \mathrm{v}^{\prime \prime}$, and $\mathrm{v}^{\prime \prime \prime}$ represent the $3 d^{10} 4 f^{0}$ electronic state corresponding to $\mathrm{Ce}^{4+}$. The presence of both the ions i.e. $\mathrm{Ce}^{4+}$ and $\mathrm{Ce}^{3+}$ over the surface of the samples indicates the redox behaviour of prepared samples [34]. Interestingly, the binding energy of the mesoporous mixed oxide was markedly shifted to lower binding energy side compared to that of pure $\mathrm{CeO}_{2}$. This interesting observation could be attributed to modification of $\mathrm{Ce}-\mathrm{O}$ environment caused by dopant ions. Figure 5a displays the O $1 \mathrm{~s} \mathrm{XP} \mathrm{spectra} \mathrm{of}$ mesoporous mixed oxides along with $\mathrm{CeO}_{2}$. Irrespective of the sample, three peaks at $\sim 528.1, \sim 532.5$, and $\sim 534.3 \mathrm{eV}$ were detected, which could be attributed to lattice oxygen, adsorbed oxygen species of hydroxyl groups, and adsorbed molecular water and/or carbonate species [35]. Two bands at $180.5-181.40 \mathrm{eV}\left(3 d_{3 / 2}\right)$ and $182.0-182.5 \mathrm{eV}\left(3 d_{5 / 2}\right)$ were observed for mesoporous $\mathrm{Ce}_{0.5} \mathrm{Zr}_{0.5} \mathrm{O}_{2}$ and $\mathrm{Ce}_{0.8} \mathrm{Zr}_{0.2} \mathrm{O}_{2}$ 
Fig. 3 FE-SEM images of a $\mathrm{CeO}_{2}, \mathbf{b} \mathrm{Ce}_{0.5} \mathrm{Zr}_{0.5} \mathrm{O}_{2}$, and $\mathbf{c}$ $\mathrm{Ce}_{0.8} \mathrm{Zr}_{0.2} \mathrm{O}_{2}$ samples

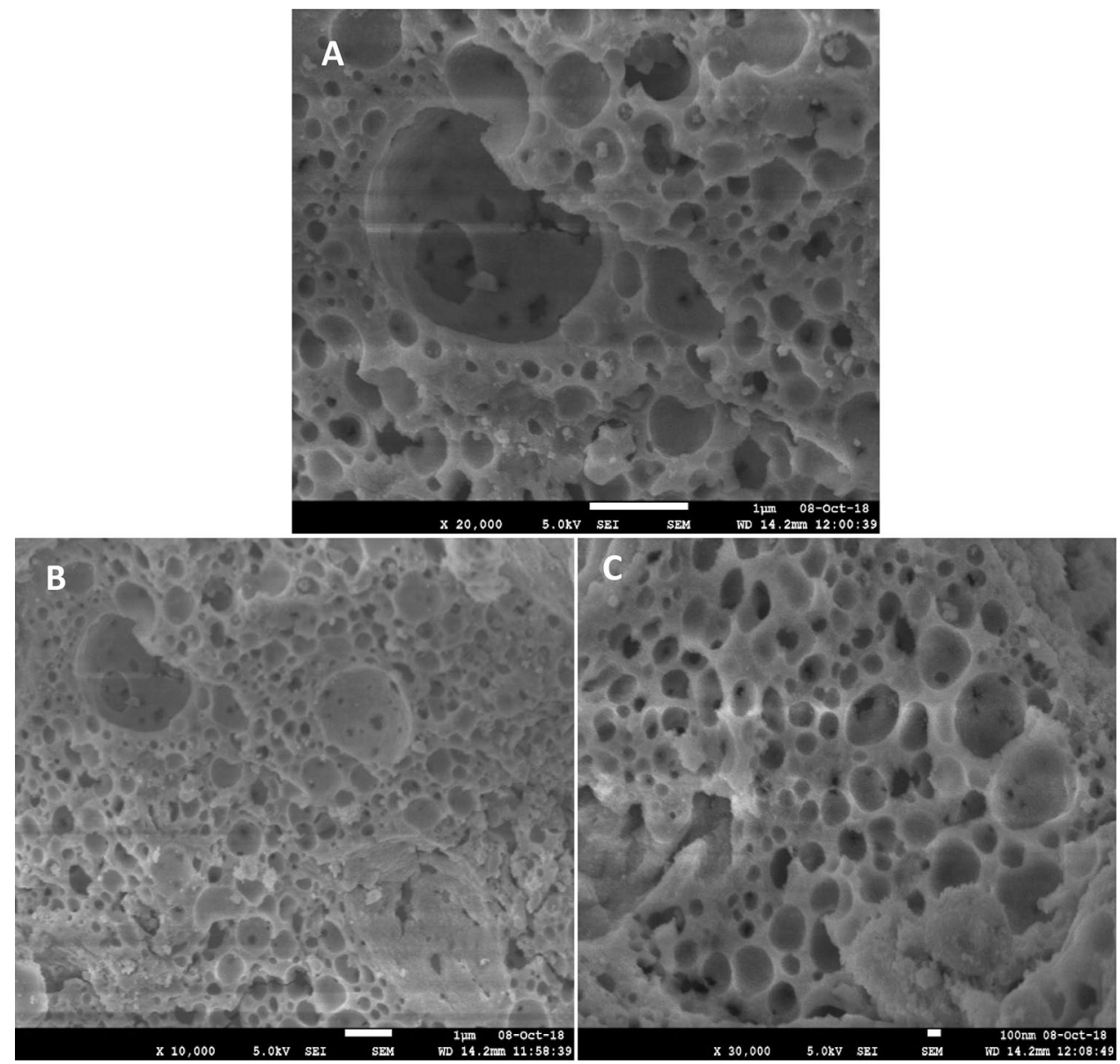

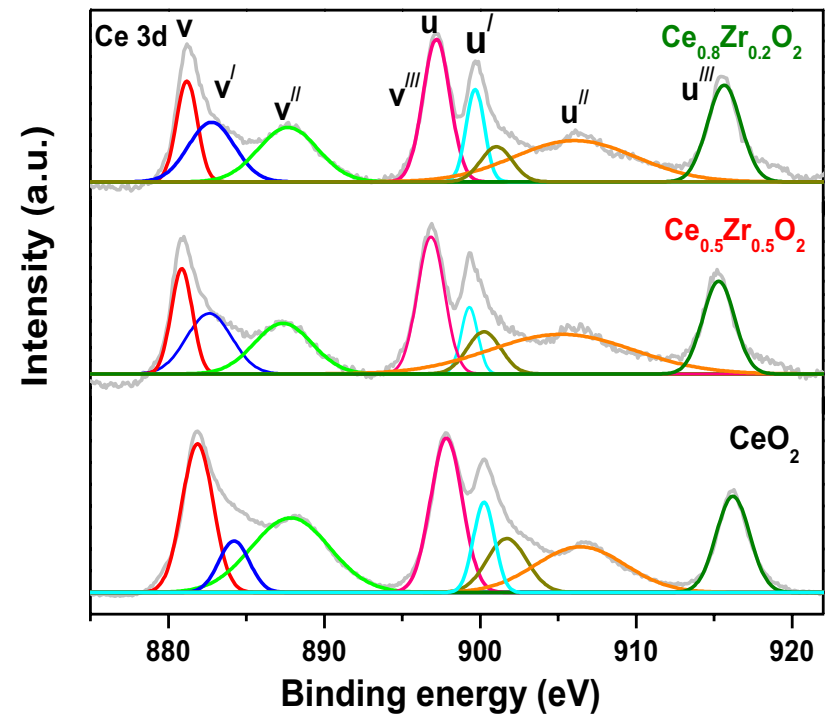

Fig. 4 Ce $3 d \mathrm{XP}$ spectra of pure $\mathrm{CeO}_{2}, \mathrm{Ce}_{0.5} \mathrm{Zr}_{0.5} \mathrm{O}_{2}$, and $\mathrm{Ce}_{0.8} \mathrm{Zr}_{0.2} \mathrm{O}_{2}$ samples

catalysts (Fig. 5B). This observation confirms the presence of $\mathrm{Zr}^{4+}$ ions in the synthesized catalysts [36].

\section{$\mathrm{H}_{2}$-TPR studies}

Figure 6 shows the $\mathrm{H}_{2}$-TPR profiles of mesoporous $\mathrm{Ce}_{0.5} \mathrm{Zr}_{0.5} \mathrm{O}_{2}$ and $\mathrm{Ce}_{0.8} \mathrm{Zr}_{0.2} \mathrm{O}_{2}$ mixed oxides including the pure $\mathrm{CeO}_{2}$ for the purpose of comparison. Typically pure $\mathrm{CeO}_{2}$ exhibits two reduction peaks at $\sim 794 \mathrm{~K}$ and $\sim 1063 \mathrm{~K}$ for surface and bulk reductions, respectively [37]. It is proven that the incorporation of metal ions into the ceria lattice remarkably improves its reducibility. It is obvious from the figure that the surface and bulk reduction peaks of $\mathrm{Ce}_{0.5} \mathrm{Zr}_{0.5} \mathrm{O}_{2}$ and $\mathrm{Ce}_{0.8} \mathrm{Zr}_{0.2} \mathrm{O}_{2}$ are considerably shifted to lower temperatures compared to pure $\mathrm{CeO}_{2}$ indicating favourable role of dopant to improve the redox ability of $\mathrm{CeO}_{2}$. Particularly in the case of $\mathrm{Ce}_{0.8} \mathrm{Zr}_{0.2} \mathrm{O}_{2}$, we observed a remarkable decrease in the surface $(618 \mathrm{~K})$ and bulk $(748 \mathrm{~K})$ reduction temperatures compared to that of $\mathrm{Ce}_{0.5} \mathrm{Zr}_{0.5} \mathrm{O}_{2}$ and $\mathrm{CeO}_{2}$ samples. This striking observation clearly demonstrates the key role of $\mathrm{Ce} / \mathrm{Zr}$ mole ratio on the reducibility of the samples. Usually redox property of the catalyst is closely associated with the formation of oxygen vacancies, which are likely to play a crucial role in the oxidation reactions. Thus, we expect more number 

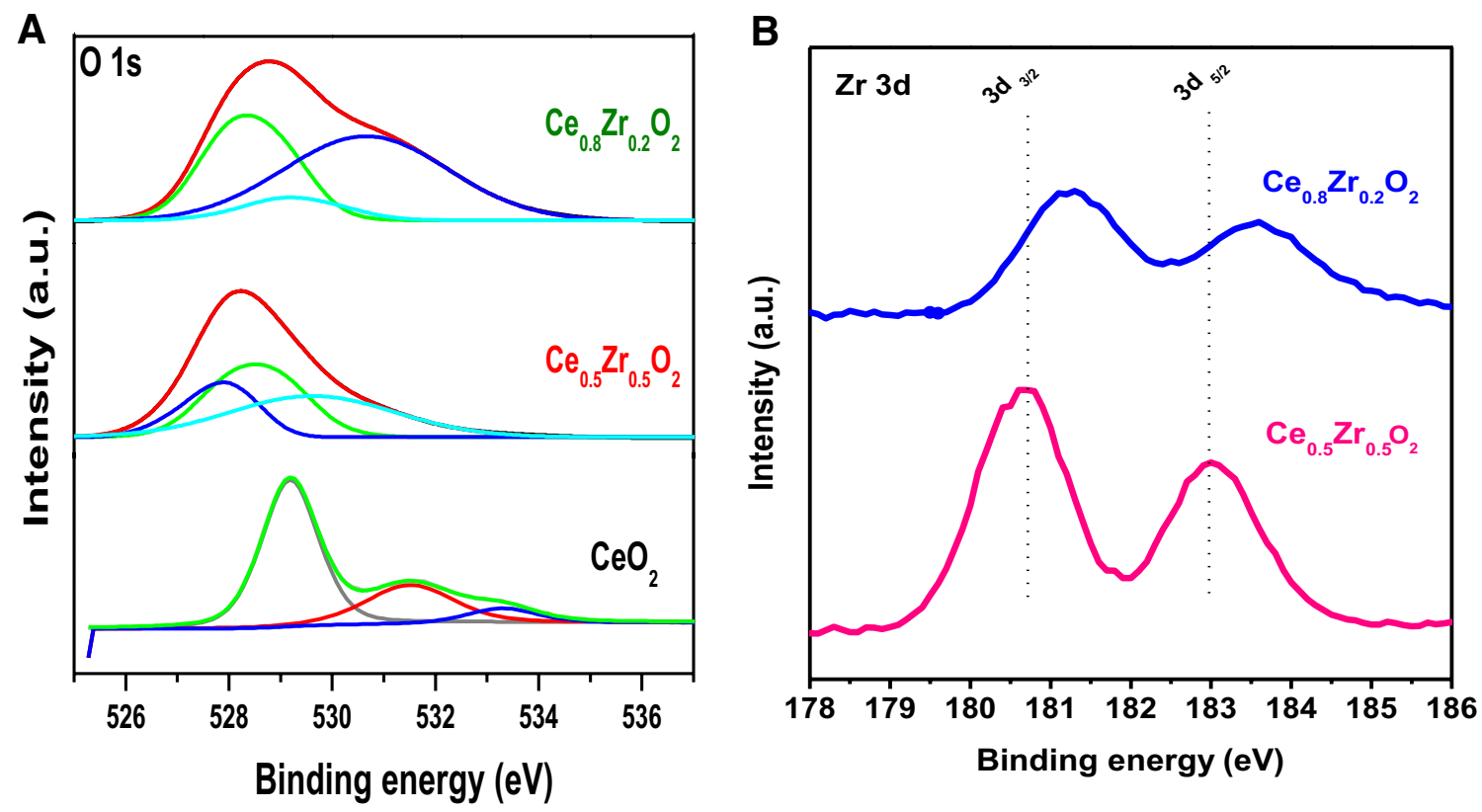

Fig. 5 a $\mathrm{O} 1 \mathrm{~s}$ and $\mathbf{b} \mathrm{Zr} 3 d \mathrm{XP}$ spectra of pure $\mathrm{CeO}_{2}, \mathrm{Ce}_{0.5} \mathrm{Zr}_{0.5} \mathrm{O}_{2}$, and $\mathrm{Ce}_{0.8} \mathrm{Zr}_{0.2} \mathrm{O}_{2}$ samples

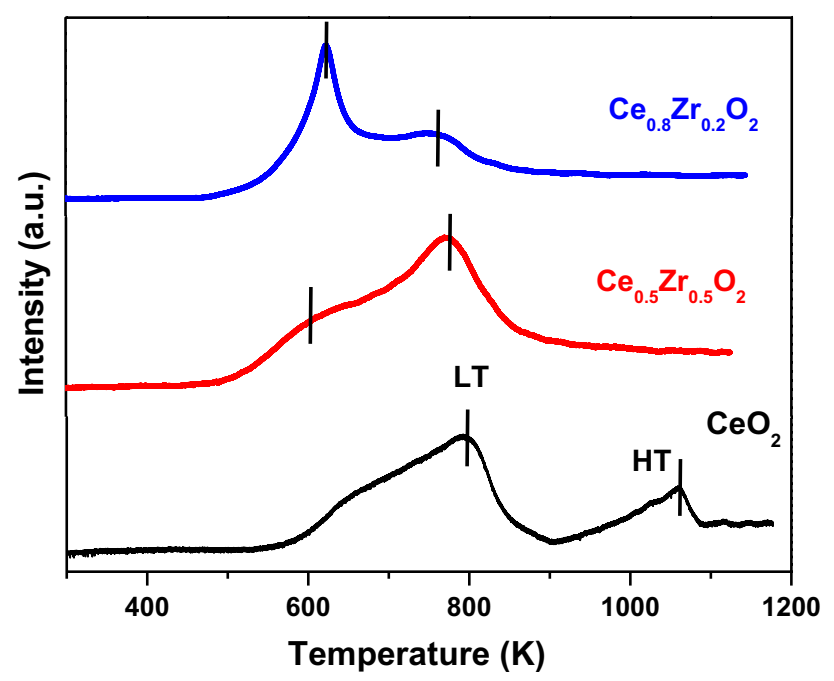

Fig. $6 \mathrm{H}_{2}$-TPR profiles of pure $\mathrm{CeO}_{2}, \mathrm{Ce}_{0.5} \mathrm{Zr}_{0.5} \mathrm{O}_{2}$, and $\mathrm{Ce}_{0.8} \mathrm{Zr}_{0.2} \mathrm{O}_{2}$ samples

of oxygen vacancies in $\mathrm{Ce}_{0.8} \mathrm{Zr}_{0.2} \mathrm{O}_{2}$ sample in line with the Raman results.

\section{Catalytic activity}

\section{Screening of catalysts}

To explore the catalytic applicability of our newly designed mesoporous mixed oxides for oxidation of olefins, styrene

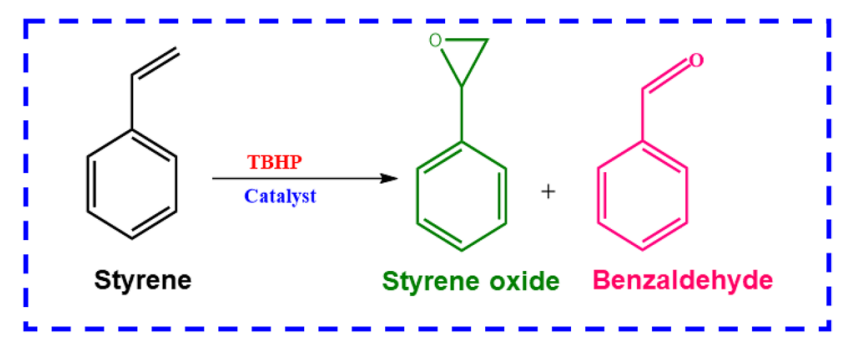

Scheme 1 Catalytic oxidation of styrene

was selected as a model reaction. The catalytic oxidation of styrene produces styrene epoxide and benzaldehyde products which are identified by GC-MS (Scheme 1). Optimization of the reaction conditions is crucial to obtain high activity and selectivity of the target product. In this direction, initially we have performed the screening of all synthesized catalysts, namely, $\mathrm{Ce}_{0.5} \mathrm{Zr}_{0.5} \mathrm{O}_{2}, \mathrm{Ce}_{0.8} \mathrm{Zr}_{0.2} \mathrm{O}_{2}$, $\mathrm{CeO}_{2}$, and $\mathrm{ZrO}_{2}$ for oxidation of styrene. The reaction was conducted at $353 \mathrm{~K}$ with isopropanol and TBHP as oxidant and solvent, respectively, for $8 \mathrm{~h}$ and the obtained results are illustrated in Table 2. Blank experiment gave poor conversion indicating the need of a catalyst to progress the styrene oxidation (Table 2, entry 1). Pure $\mathrm{CeO}_{2}$ and $\mathrm{ZrO}_{2}$ oxides showed $\sim 36$ and $\sim 24 \%$ conversion with $\sim 80$ and $\sim 68 \%$ selectivity to styrene epoxide, respectively (Table 2, entries 2 and 3 ). This result indicates that $\mathrm{CeO}_{2}$ is relatively active and selective to styrene epoxide compared to that of $\mathrm{ZrO}_{2}$. 
Table 2 Oxidation of styrene to styrene epoxide (SO) and benzaldehyde (BA) over $\mathrm{Ce}-\mathrm{Zr}$ mixed oxide catalyst with different $\mathrm{Ce} / \mathrm{Zr}$ mole ratios and other catalysts

\begin{tabular}{llllll}
\hline Entry & Catalyst & $\begin{array}{l}\text { Conver- } \\
\text { sion } \\
(\%)\end{array}$ & $\begin{array}{l}\text { Selectivity } \\
\text { to } \mathrm{SO}(\%)\end{array}$ & $\begin{array}{l}\text { Selectivity } \\
\text { to BA }(\%)\end{array}$ & Others (\%) \\
\hline 1 & $\mathrm{Blank}$ & 4.5 & - & - & - \\
2 & $\mathrm{CeO}_{2}$ & 36 & 80 & 11 & 9 \\
3 & $\mathrm{ZrO}_{2}$ & 24 & 68 & 9 & 23 \\
$4^{\mathrm{a}}$ & $\mathrm{CeO}_{2}$ & 28 & 70 & 18 & 12 \\
$5^{\mathrm{b}}$ & $\mathrm{ZrO}_{2}$ & 20 & 65 & 10 & 25 \\
6 & $\mathrm{Ce}_{0.5} \mathrm{Zr}_{0.5} \mathrm{O}_{2}$ & 76 & 83 & 12 & 5 \\
7 & $\mathrm{Ce}_{0.8} \mathrm{Zr}_{0.2} \mathrm{O}_{2}$ & 98 & 90 & 8 & 2 \\
$8^{\mathrm{c}}$ & $\mathrm{Ce}_{0.8} \mathrm{Zr}_{0.2} \mathrm{O}_{2}$ & 75 & 70 & 15 & 15 \\
\hline
\end{tabular}

Reaction conditions: Styrene (4 mmol), catalyst (100 mg), TBHP oxidant, isopropanol $(5 \mathrm{ml})$, time $(8 \mathrm{~h})$, and temperature $(353 \mathrm{~K})$

${ }^{\mathrm{a}, \mathrm{b}}$ Nanocrystalline oxides prepared by co-precipitation method

${ }^{\mathrm{c}} \mathrm{Ce}-\mathrm{Zr}$ mixed oxide prepared by co-precipitation method

To know the significance of the morphology of the samples, we have conducted the reaction using nanocrystalline $\mathrm{CeO}_{2}$ and $\mathrm{ZrO}_{2}$ catalysts under identical conditions that provided $\sim 28$ and $\sim 20 \%$ styrene conversion, respectively, (Table 2, entries 4 and 5), confirming the key role of catalyst morphology for styrene oxidation.

Later, we studied the influence of $\mathrm{Ce} / \mathrm{Zr}$ mole ratio towards oxidation of styrene. For this purpose, $\mathrm{Ce}-\mathrm{Zr}$ mixed oxides with different $\mathrm{Ce} / \mathrm{Zr}$ mole ratios were tested under same reaction conditions and the obtained results are compiled in Table 2. As can be noted from the Table 2, both conversion and selectivity are significantly varied with the change of Ce/ $\mathrm{Zr}$ mole ratio (Table 2). The $\mathrm{Ce}_{0.5} \mathrm{Zr}_{0.5} \mathrm{O}_{2}$ catalyst provided $\sim 76 \%$ conversion with $\sim 83 \%$ and $12 \%$ selectivity to styrene epoxide and benzaldehyde, respectively (Table 2, entry 6). As the concentration of Ce increases, the conversion of styrene increased from $\sim 83$ to $~ 98 \%$ with $\sim 90$ and $\sim 8 \%$ selectivity of styrene epoxide and benzaldehyde, respectively (Table 2, entry 7 ). A high catalytic efficacy of $\mathrm{Ce}_{0.8} \mathrm{Zr}_{0.2} \mathrm{O}_{2}$ mixed oxide could be attributed to larger BET surface area, more defect sites (oxygen vacancies), and high reducibility supported by XRD, BET, FE-SEM, and $\mathrm{H}_{2}$-TPR studies. Meanwhile, to confirm the influence of morphology, nanocrystalline $\mathrm{Ce}_{0.5} \mathrm{Zr}_{0.5} \mathrm{O}_{2}$ prepared by coprecipitation method was also tested for styrene oxidation under same reaction conditions and it showed relatively less activity than the mesoporous $\mathrm{Ce}_{0.8} \mathrm{Zr}_{0.2} \mathrm{O}_{2}$ mixed oxide (Table 2, entry 8).

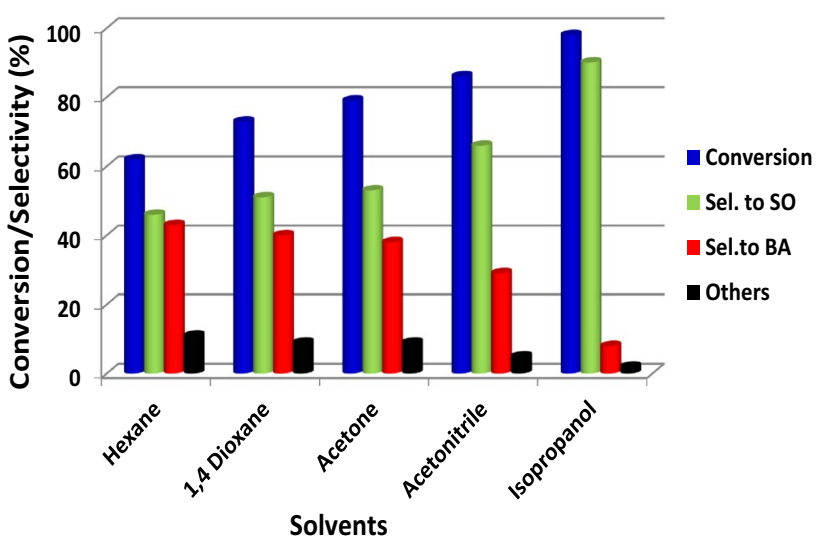

Fig. 7 Effect of solvent on the oxidation of styrene to styrene epoxide (SO) and benzaldehyde (BA) over $\mathrm{Ce}_{0.8} \mathrm{Zr}_{0.2} \mathrm{O}_{2}$ catalyst. Reaction conditions: Styrene $(4 \mathrm{mmol})$, time $(8 \mathrm{~h})$, temperature $(353 \mathrm{~K})$, catalyst $(50 \mathrm{mg})$, TBHP, and isopropanol $(3 \mathrm{~mL})$

\section{Effect of solvent}

To understand the role of polarity of solvent on styrene oxidation, variety of solvents were explored at $353 \mathrm{~K}$ for $8 \mathrm{~h}$ using TBHP as the oxidant with mesoporous $\mathrm{Ce}_{0.8} \mathrm{Zr}_{0.2} \mathrm{O}_{2}$ mixed oxide catalyst and the achieved results are shown in Fig. 7. From the figure it is believed that polarity of solvent highly influences the activity and selectivity of the catalysts. Use of non-polar solvents like hexane shows $~ 62 \%$ styrene conversion, and this is due to the low solubility of the styrene in hexane solvent. In the case of polar solvents, four different solvents were tested and the results reveal an enhancement in the conversion of styrene with the increase of solvent polarity. Interestingly, we observed $\sim 73, \sim 79,86$, and $~ 98 \%$ conversion for 1,4-dioxane, acetone, acetonitrile, and isopropanol solvents, respectively. A high activity and selectivity of styrene epoxide ( 90\%) was achieved with isopropanol solvent. High oxygen solubility in isopropanol solvent is likely to be the probable reason for this result. Therefore, we have considered isopropanol as the suitable solvent to optimize the other reaction parameters for this reaction.

\section{Effect of reaction temperature}

The effect of reaction temperature on the oxidation of styrene was examined in the range of 323-363 $\mathrm{K}$ over the highly active $\mathrm{Ce}_{0.8} \mathrm{Zr}_{0.2} \mathrm{O}_{2}$ catalyst using TBHP as the oxidant in isopropanol solvent. The obtained results are presented in Fig. 8. As expected, conversion of styrene is increased with the raise of reaction temperature. Obviously, reaction temperature had notable effect on styrene

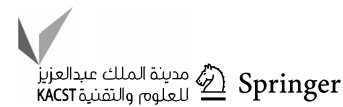




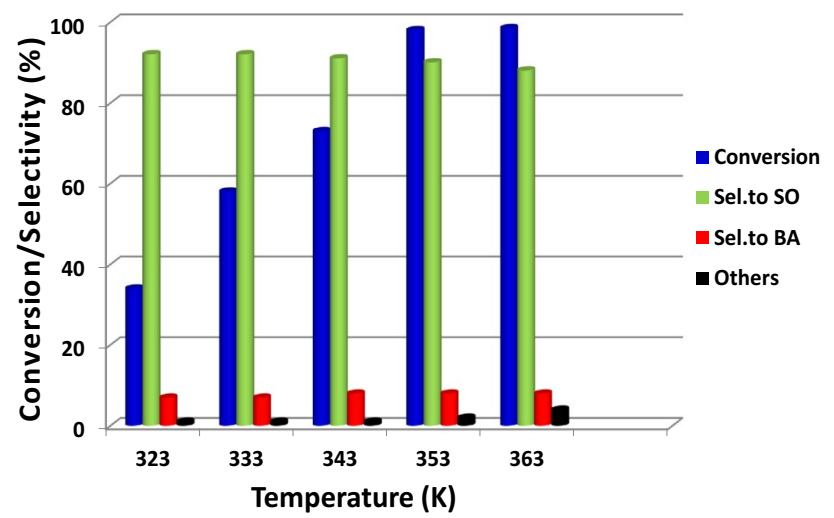

Fig. 8 Effect of reaction temperature on the oxidation of styrene to styrene epoxide (SO) and benzaldehyde (BA) over $\mathrm{Ce}_{0.8} \mathrm{Zr}_{0.2} \mathrm{O}_{2}$ catalyst. Reaction conditions: Styrene $(4 \mathrm{mmol})$, time $(8 \mathrm{~h})$, catalyst $(50 \mathrm{mg}), \mathrm{TBHP}$, and isopropanol $(3 \mathrm{~mL})$

oxidation in terms of conversion and selectivity of the target product. It can be clearly seen that the conversion of styrene gradually increases from $\sim 34$ to $\sim 98 \%$ with the increase of reaction temperature from 323 to $353 \mathrm{~K}$. Particularly, there was no significant variation in the selectivity of styrene epoxide $(\sim 88-92 \%)$ with the reaction temperature. Further increasing the temperature from 353 to $363 \mathrm{~K}$, no considerable variation in the conversion of styrene $(\sim 98.5 \%)$ was observed but the selectivity of styrene epoxide was slightly dropped to $\sim 88 \%$. Therefore, the $353 \mathrm{~K}$ is considered as an optimum temperature for further studies.

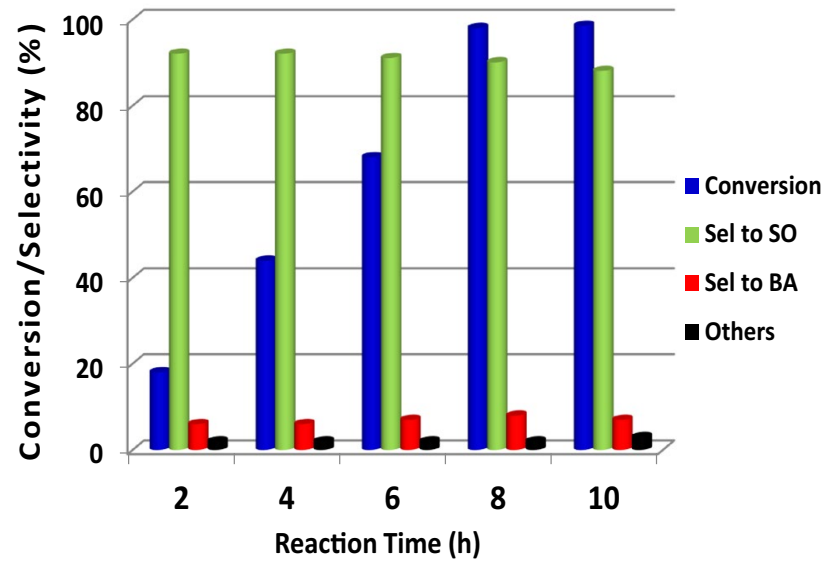

Fig. 9 Effect of reaction time on the selective oxidation of styrene to styrene epoxide (SO) and benzaldehyde (BA) over $\mathrm{Ce}_{0.8} \mathrm{Zr}_{0.2} \mathrm{O}_{2}$ catalyst. Reaction conditions: Styrene (4 mmol), temperature (353 K), catalyst $(50 \mathrm{mg}), \mathrm{TBHP}$, and isopropanol $(3 \mathrm{~mL})$

\section{Effect of reaction time}

The effect of reaction time on the activity and distribution of products for styrene oxidation was studied over the $\mathrm{Ce}_{0.8} \mathrm{Zr}_{0.2} \mathrm{O}_{2}$ catalyst at $353 \mathrm{~K}$ using TBHP as the oxidant in isopropanol solvent and the obtained results are compiled in Fig. 9. As can be seen from the figure, conversion of styrene increases with the increase of reaction time. The conversion as well as selectivity of styrene epoxide was found to increase with the increasing of reaction time from 2 to $8 \mathrm{~h}$. The achieved styrene conversions were $\sim 18, \sim 44, \sim 68$, and $\sim 98 \%$ for $2,4,6$, and $8 \mathrm{~h}$ of reaction times, respectively. Further increase of reaction time from 8 to $10 \mathrm{~h}$, no variation in the conversion of styrene was observed. Thus, we consider $8 \mathrm{~h}$ as the optimum reaction time for the oxidation of styrene.

\section{Effect of styrene/TBHP molar ratio}

The influence of styrene/TBHP molar ratio was examined for oxidation of styrene at $353 \mathrm{~K}$ for $8 \mathrm{~h}$ and the obtained results are shown in Fig. 10. The styrene conversion was found to be low at low styrene/TBHP mole ratio due to less availability of reactive oxygen to interact with the substrate. Conversion of styrene considerably increases with the increase of styrene/TBHP molar ratio, which is due to the fact that more number of TBHP molecules adsorb on the active sites, thereby leading to higher activity by interacting with more number of styrene molecules. The achieved styrene conversions are $\sim 45, \sim 66, \sim 98$, and $\sim 99 \%$ for 1:0.50, 1:1, 1:2, and 1:4 mol ratios, respectively. Interestingly, we found high selectivity to styrene epoxide at all ratios. Therefore, these promising results clearly illustrated the remarkable role of

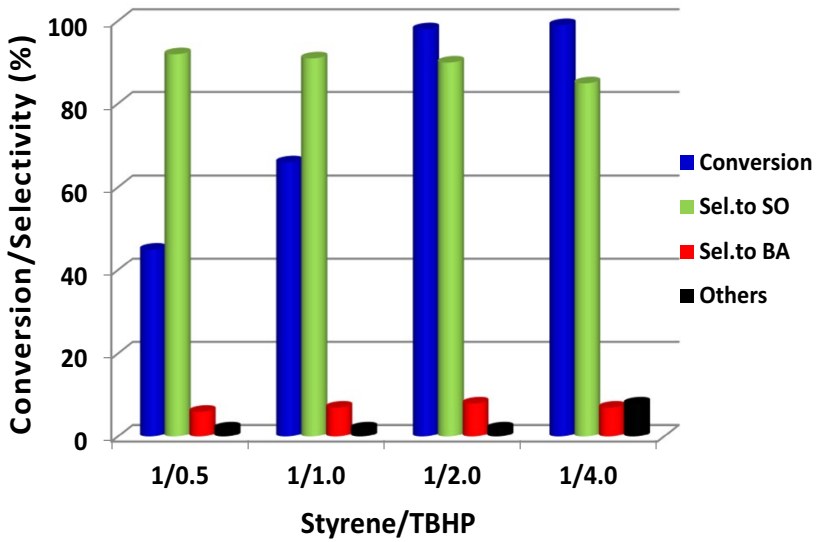

Fig. 10 Effect of styrene/TBHP mole ratio on styrene oxidation to styrene epoxide (SO) and benzaldehyde (BA) over $\mathrm{Ce}_{0.8} \mathrm{Zr}_{0.2} \mathrm{O}_{2}$ catalyst. Reaction conditions: Styrene $(4 \mathrm{mmol})$, time $(8 \mathrm{~h})$, temperature $(353 \mathrm{~K})$, catalyst $(50 \mathrm{mg})$, TBHP, and isopropanol $(3 \mathrm{~mL})$ 


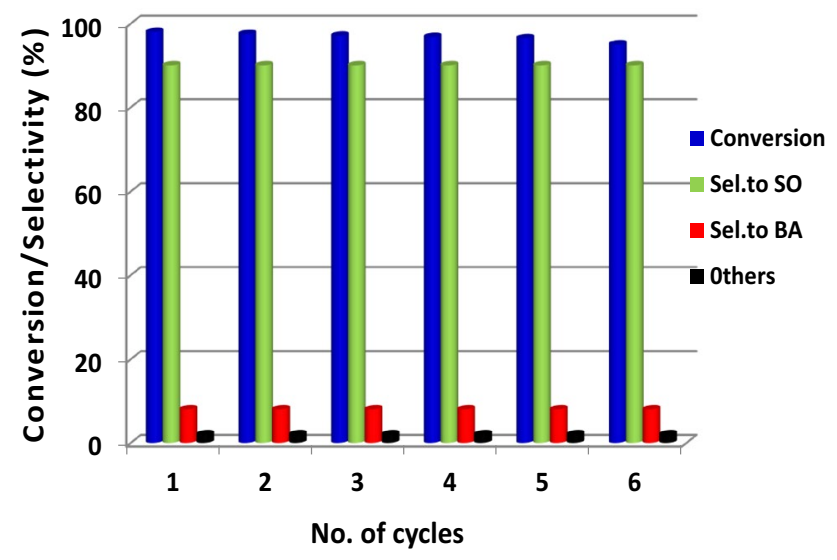

Fig. 11 Recyclability of $\mathrm{Ce}_{0.8} \mathrm{Zr}_{0.2} \mathrm{O}_{2}$ catalyst for styrene oxidation to styrene epoxide (SO) and benzaldehyde (BA). Reaction conditions: Styrene $(4 \mathrm{mmol})$, time $(8 \mathrm{~h})$, temperature $(353 \mathrm{~K})$, catalyst $(50 \mathrm{mg})$, TBHP, and isopropanol $(3 \mathrm{~mL})$

cyclohexene/TBHP molar ratio for this reaction in terms of conversion and distribution of products.

\section{Reusability}

Finally, we have studied the efficiency of $\mathrm{Ce}_{0.8} \mathrm{Zr}_{0.2} \mathrm{O}_{2}$ catalyst up to 6 cycles to assess its reusability for styrene oxidation using TBHP as the oxidant in isopropanol solvent. The obtained results are presented in Fig. 11. The fixed reaction parameters for these studies were as follows: styrene (4 mmol), catalyst amount $(50 \mathrm{mg})$, isopropanol $(3 \mathrm{~mL})$, reaction time $(8 \mathrm{~h})$, and temperature $(353 \mathrm{~K})$. After completion of each cycle, the solid catalyst was recovered from the reaction mixture by means of centrifugation, washed several times with ethanol to remove reaction gradients and then dried at $423 \mathrm{~K}$ for $2 \mathrm{~h}$. Remarkably no variation in the catalytic activity of $\mathrm{Ce}_{0.8} \mathrm{Zr}_{0.2} \mathrm{O}_{2}$ was found up to 6 cycles for the styrene oxidation. The achieved styrene conversions were $\sim 98, \sim 97.5, \sim 97.1, \sim$ $96.8, \sim 96.5$ and $\sim 95 \%$ for 1st, 2nd, 3rd, 4th, 5th and 6th cycles, respectively. Also, no considerable variation in the selectivity of styrene epoxide product was observed with the repeated use of catalyst.

\section{Conclusion}

In this work, mesoporous $\mathrm{Ce}-\mathrm{Zr}$ mixed oxides with different $\mathrm{Ce} / \mathrm{Zr}$ mole ratios along with $\mathrm{CeO}_{2}$ and $\mathrm{ZrO}_{2}$ were synthesized by inverse micelle template self-assembly method, characterized by various techniques and evaluated for styrene oxidation. Characterization studies reveal that the $\mathrm{Ce} / \mathrm{Zr}$ mole ratio precisely modifies the physicochemical properties of the $\mathrm{Ce}-\mathrm{Zr}$ metal oxide catalysts. Among the investigated catalysts, the $\mathrm{Ce}_{0.8} \mathrm{Zr}_{0.2} \mathrm{O}_{2}$ combination exhibited high styrene conversion ( 98\%) followed by $\mathrm{Ce}_{0.8} \mathrm{Zr}_{0.2} \mathrm{O}_{2}(76 \%)$, $\mathrm{CeO}_{2}(36 \%)$ and $\mathrm{ZrO}_{2}(24 \%)$ after $8 \mathrm{~h}$ of reaction at $353 \mathrm{~K}$. It was proved that $\mathrm{Ce} / \mathrm{Zr}$ mole ratio and morphology had a remarkable influence on the catalytic performance and selectivity of the products. A larger BET surface area, more defect sites, and strong synergetic interaction were identified as the key factors in achieving high activity and superior selectivity to styrene epoxide for the $\mathrm{Ce}-\mathrm{Zr}$ mixed oxide catalyst. Further, optimization of various reaction parameters was accomplished using highly active catalyst and its recyclability was studied up to six cycles with consistent results.

Acknowledgements PRGNR and BG thank the Council of Scientific and Industrial Research (CSIR), New Delhi, for the award of research fellowships. BMR thanks the Department of Atomic Energy (DAE), Mumbai, for the award of the Raja Ramanna Fellowship. Authors thank Director, CSIR-IICT, for the support of this work.

Open Access This article is licensed under a Creative Commons Attribution 4.0 International License, which permits use, sharing, adaptation, distribution and reproduction in any medium or format, as long as you give appropriate credit to the original author(s) and the source, provide a link to the Creative Commons licence, and indicate if changes were made. The images or other third party material in this article are included in the article's Creative Commons licence, unless indicated otherwise in a credit line to the material. If material is not included in the article's Creative Commons licence and your intended use is not permitted by statutory regulation or exceeds the permitted use, you will need to obtain permission directly from the copyright holder. To view a copy of this licence, visit http://creativecommons.org/licenses/by/4.0/.

\section{References}

1. Zhang L, Zhang Z, He X, Zhang F, Zhang Z (2017) Regulation of the products of styrene oxidation. Chem Eng Res Des 120:171

2. Desai NC, Chudasama JA, Karkar TJ, Patel BY, Jadeja KA, Godhani DR, Mehta JP (2016) Studies of styrene oxidation by catalyst based on Zeolite-Y nanohybrid materials. J Mol Catal A $424: 203$

3. Masunga N, Tito GS, Meijboom R (2018) Catalytic evaluation of mesoporous metal oxides for liquid phase oxidation of styrene. Appl Catal A 552:154

4. Liua X, Dinga J, Lina X, Gaob R, Lia Z, Daia WL (2015) Zrdoped $\mathrm{CeO}_{2}$ nanorods as versatile catalyst in the epoxidation of styrene with tert-butyl hydroperoxide as the oxidant. Appl Catal A 503:117

5. Sebastian J, Jinka KM, Jasra RV (2006) Effect of alkali and alkaline earth metal ions on the catalytic epoxidation of styrene with molecular oxygen using cobalt(II)-exchanged zeolite X. J Catal 244:208

6. Noh J-H, Patala R, Meijboom R (2016) Catalytic evaluation of dendrimer and reverse microemulsion template $\mathrm{Pd}$ and $\mathrm{Pt}$ nanoparticles for the selective oxidation of styrene using TBHP. Appl Catal A 514:253

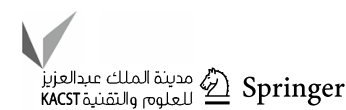


7. Pawar RY, Pardeshi SK (2018) Selective oxidation of styrene to benzaldehyde using soft $\mathrm{BaFe}_{2} \mathrm{O}_{4}$ synthesized by citrate gel combustion method. Arabian J Chem 11:282

8. Thao N, Trung HH (2014) Selective oxidation of styrene over $\mathrm{Mg}-\mathrm{Co}-\mathrm{Al}$ hydrotalcite like-catalysts using air as oxidant. Catal Commun 45:153

9. Lu X, Yuan Y (2009) Copper-containing hexagonal mesoporous silicas for styrene epoxidation using tert-butylhydroperoxide. Appl Catal A 365:180

10. Sharma S, Sinha S, Chand S (2012) Polymer anchored catalysts for oxidation of styrene using TBHP and molecular oxygen. Ind Eng Chem Res 51:8806

11. Jain R, Gopinath CS (2019) Morphology-dependent green and selective catalytic styrene oxidation on $\mathrm{Co}_{3} \mathrm{O}_{4}$. Dalton Trans 48:4574

12. Tang J, Yang XL, Zhang XW, Wang M, Wu CD (2010) A functionalized polyoxometalate solid for selective oxidation of styrene to benzaldehyde. Dalton Trans 39:3396

13. Tong J, Cai X, Wang H, Zhang Q (2014) Improvement of catalytic activity in selective oxidation of styrene with $\mathrm{H}_{2} \mathrm{O}_{2}$ over spinel $\mathrm{Mg}-\mathrm{Cu}$ ferrite hollow Spheres in water. Mater Res 55:205

14. Thao NT, Huyen LTK (2015) Catalytic oxidation of styrene over Cu-doped hydrotalcite. Chem Eng 279:840

15. Hu R, Yang P, Pan Y, Li Y, He Y, Feng J, Li D (2017) Synthesis of a highly dispersed $\mathrm{CuO}$ catalyst on CoAl-HT for the epoxidation of styrene. Dalton Trans 46:13463

16. Nongwe IB, Ravat V, Meijboom R, Coville NJ (2013) Efficient and reusable $\mathrm{Co} /$ nitrogen doped hollow carbon sphere catalysts for the aerobic oxidation of styrene. Appl Catal A 466:1

17. Nemanashi M, Meijboom R (2013) Dendrimer derived titaniasupported $\mathrm{Au}$ nanoparticles as potential catalysts in styrene oxidation. Catal Lett 143:324

18. Song W, Poyraz AS, Meng Y, Ren Z, Chen SY, Suib SL (2014) Mesoporous $\mathrm{Co}_{3} \mathrm{O}_{4}$ with controlled porosity: inverse micelle synthesis and high-performance catalytic $\mathrm{CO}$ oxidation at -60 ${ }^{\circ} \mathrm{C}$. Chem Mater 26:629

19. Sui M, Liu J, Sheng L (2011) Mesoporous material supported manganese oxides $\left(\mathrm{MnO}_{\mathrm{x}} / \mathrm{MCM}-41\right)$ catalytic ozonation of nitrobenzene in water. Appl Catal B 106:195

20. Taguchi A, Schüth F (2005) Ordered mesoporous materials in catalysis. Microporous Mesoporous Mater 77:1

21. Weerakkody C, Biswas S, Song W, He J, Wasalathanthri N, Dissanayake S, Kriz DA, Dutta B, Suib SL (2018) Controllable synthesis of mesoporous cobalt oxide for peroxide free catalytic epoxidation of alkenes under aerobic conditions. Appl Catal B 221:681

22. Rao BG, Sudarsanam P, Nallappareddy PRG, Reddy MY, Rao TV, Reddy BM (2017) Selective allylic oxidation of cyclohexene catalyzed by nanostructured $\mathrm{Ce}-\mathrm{Sm}-\mathrm{Si}$ materials. Catal Commun 101:57

23. Wang WW, Yu WZ, Du PP, Xu H, Jin Z, Si R, Ma C, Shi S, Jia CJ, Yan CH (2017) Crystal plane effect of ceria on supported copper oxide cluster catalyst for $\mathrm{CO}$ oxidation: Importance of metal-support interaction. ACS Catal 7:1313

24. Rao BG, Sudarsanam P, Mallesham B, Reddy BM (2016) Highly efficient continuous-flow oxidative coupling of amines using promising nanoscale $\mathrm{CeO}_{2}-\mathrm{M} / \mathrm{SiO}_{2}\left(\mathrm{M}=\mathrm{MoO}_{3}\right.$ and $\left.\mathrm{WO}_{3}\right)$ solid acid catalysts. RSC Adv 6:95252
25. Tamura M, Sawabe K, Tomishige K, Satsuma A, Shimizu K (2015) Substrate-specific heterogeneous catalysis of $\mathrm{CeO}_{2}$ by entropic effects via multiple interactions. ACS Catal 5:20

26. Devaiah D, Reddy LH, Park S-E, Reddy BM (2018) Ceria-zirconia mixed oxides: synthetic methods and applications. Catal Rev Sci Eng 60:177

27. Nallappareddy PRG, Rao BG, Rao TV, Reddy BM (2019) Selective aerobic oxidation of vanillyl alcohol to vanillin catalysed by nanostructured Ce-Zr-O solid solutions. Catal Lett 149:533

28. Niluka D, Wasalathanthri, Thomas M, Santa M, Kriz DA, Dissanayake SL, Kuo CH, Biswas S, Suib SL (2017) Mesoporous manganese oxides for $\mathrm{NO}_{2}$ assisted catalytic soot oxidation. Appl Catal B 201:543

29. Li J, Liu X, Zhan W, Guo Y, Guo Y, Lu G (2016) Preparation of high oxygen storage capacity and thermally stable ceria-zirconia solid solution. Catal Sci Technol 6:897

30. Rao BG, Sudarsanam P, Nallappareddy PRG, Reddy MY, Rao TV, Reddy BM (2018) Selective allylic oxidation of cyclohexene over a novel nanostructured $\mathrm{CeO}_{2}-\mathrm{Sm}_{2} \mathrm{O}_{3} / \mathrm{SiO}_{2}$ catalyst. Res Chem Intermed 44:6151

31. Sudarsanam P, Hillary B, Mallesham B, Rao BG, Amin MH, Nafady A, Alsalme AM, Reddy BM, Bhargava SK (2016) Designing $\mathrm{CuO}_{x}$ nanoparticle-decorated $\mathrm{CeO}_{2}$ nanocubes for catalytic soot oxidation: Role of the nanointerface in the catalytic performance of heterostructured nanomaterials. Langmuir 32:2208

32. Rao BG, Jampaiah D, Venkataswamy P, Reddy BM (2016) Enhanced catalytic performance of manganese and cobalt codoped $\mathrm{CeO}_{2}$ catalysts for diesel soot oxidation. ChemSelect $1: 6681$

33. Sudarsanam P, Hillary B, Amin MH, Hamid SBA, Bhargava SK (2016) Structure-activity relationships of nanoscale $\mathrm{MnO}_{\mathrm{x}} / \mathrm{CeO}_{2}$ heterostructured catalysts for selective oxidation of amines under eco-friendly conditions. Appl Catal B 185:213

34. Lin X, Zhao S, Fu L, Luo Y, Zhu R, Liu Z (2017) Synthesis of Co-N-C grafted on well-dispersed $\mathrm{MnO}_{\mathrm{x}}-\mathrm{CeO}_{2}$ hollow mesoporous sphere with efficient catalytic performance. Mol Catal 437:18

35. Rao BG, Sudarsanam P, Rangaswamy A, Reddy BM (2015) Highly efficient $\mathrm{CeO}_{2}-\mathrm{MoO}_{3} / \mathrm{SiO}_{2}$ catalyst for solvent-free oxidative coupling of benzylamines into $\mathrm{N}$-benzylbenzaldimines with $\mathrm{O}_{2}$ as the oxidant. Catal Lett 145:1436

36. Liu B, Li C, Zhang G, Yao X, Chuang SSC, Li Z (2018) Oxygen vacancy promoting dimethyl carbonate synthesis from $\mathrm{CO}_{2}$ and methanol over $\mathrm{Zr}$-doped $\mathrm{CeO}_{2}$ nanorods. ACS Catal 8:10446

37. Mandala S, Santra C, Bando KK, James O, Maity S, Mehtad D, Chowdhury B (2013) Aerobic oxidation of benzyl alcohol over mesoporous Mn-doped ceria supported Au nanoparticle catalyst. J Mol Catal A 378:47

Publisher's Note Springer Nature remains neutral with regard to jurisdictional claims in published maps and institutional affiliations. 